REVISTA DE DERECHO UNED, NÚM. 24, 2019

\title{
OPERAE LIBERALES: CONSIDERACIÓN SOCIAL Y ASPECTOS JURÍDICOS RELEVANTES DE LAS PROFESIONES LIBERALES EN LA ROMA ANTIGUA
}

\author{
OPERAE LIBERALES: SOCIAL CONSIDERATION AND \\ RELEVANT LEGAL ASPECTS OF LIBERAL PROFESSIONS \\ IN ANCIENT ROME
}

JonATAN TobÍo FERnÁNDEZ

Abogado en ejercicio.

Doctorando adscrito al programa de Ciencias Jurídicas y Sociales de la Escuela de Doctorado de la Universidad Nacional de Educación

a Distancia (UNED)

Resumen: En la Grecia y Roma clásicas, en donde cimientan los fundamentos estructurales de nuestra actual civilización, van a otorgar la más alta consideración al ser humano dedicado al desarrollo del intelecto, con un otium encaminado al cultivo de la mente y dedicado a una ocupación relacionada con algún ámbito del saber que requiera el uso del conocimiento y el dominio de una lex artis - no obstante, adquiere también relevancia el cultivo del cuerpo, pero, por lo general, en aras de una correcta instrucción militar, al objeto de prestar servicio, si fuere necesario, en defensa de la comunidad o sociedad-. La Roma clásica, que absorbe el pensamiento de los filósofos griegos — sobre todo, el arte de la retórica y la elocuencia-, a semejanza de la propia Grecia, distinguirá aquellos trabajos manuales, dependientes y serviles, que Cicerón califica como viles, en los que para su realización, por regla general, se imprime esfuerzo físico y para los que, en algunos casos, se requiere el dominio de un arte, pero que, en otros, ni tan siquiera se precisa el conocimiento previo 
de técnica alguna $-\mathrm{O}$, de necesitarse, se trataría de un mínimo modus operandi-, de aquellas otras actividades en las que, para su fiel desempeño, es imprescindible poseer rigurosos conocimientos teóricos y prácticos, por lo que traen consigo una considerable carga intelectual, así como, en su ejecución, se caracterizan por su autonomía, lo que implica alto grado de libertad e independencia. Estas notas, que han perdurado a lo largo de la historia, en la actualidad continúan funcionando como elementos que, al valorarse en su conjunto, distinguen a las denominadas en la actualidad profesiones liberales del resto de profesiones, oficios u ocupaciones.

Palabras clave: Trabajo, profesión liberal, profesión intelectual, mandato, honorarios.

Abstract: In classical Greece and Rome, where the foundations of our present civilization were laid, they regarded most highly human beings dedicated to developing their intellect, with an otium intended for the cultivation of the mind and dedicated to an occupation associated with a field of knowledge that requires the use of expertise and the mastery of a lex artis - although the cultivation of the body also acquires importance for the purpose of correct military instruction to serve in defense of the community or society if needed-. Classical Rome, which absorbed Greek philosophy —especially the rhetorical art of eloquence-, like Greece itself, made a distinction between manual, dependent and servile labor, which Cicero considered base, which require physical force as a general rule and which in some cases also require the mastery of an art, but in other do not even demand prior knowledge of a technique - and if they do it would be merely a modus operandi-, and other activities where it is indispensable for their correct practice to possess rigorous theoretical and practical knowledge. The latter entail a considerable intellectual onus, and their practice is characterized by autonomy, which implies a high degree of freedom and independence. These features, which have continued throughout history, currently continue to function as elements which, if taken as a group, set apart in the present day the liberal professions from the rest of professions, trades or occupations.

Keywords: Labor, liberal profession, intellectual profession, mandate, fees.

Recepción original: 31/01/2019

Aceptación original: 24/04/2019 
Sumario: I. Visión del trabajo en la Grecia antigua. II. Proyección de las concepciones griegas en Roma. III. Las profesiones liberales en el mundo romano antiguo. III.A. Ulpiano y la reclamación de los honorarios. III.B. Referencia a las distintas profesiones liberales. III.B.1. Praeceptores studiorum liberalium. III.B.2. Advocati. III.B.3. Praeceptores directo civil. III.B.4. Philosophi. III.B.5. Agrimensores. III.B.6. Medici. IV. Naturaleza jurídica de las relaciones privadas que establecen estos profesionales con sus clientes en el desempeño de la actividad que les es propia. V. Conclusión.

\section{VISIÓN DEL TRABAJO EN LA GRECIA ANTIGUA}

Tanto en la Grecia como en la Roma antigua, el trabajo no es concebido con connotaciones positivas. Si en la actualidad se entiende el trabajo, en su sentido amplio, como un instrumento o valor esencial para la realización del ser humano, en su dignidad individual y en su proyección social ${ }^{1}$, ello no ocurre así en el mundo antiguo, en el que tiene una concepción muy distinta.

Battaglia $^{2}$ señala que, en la antigüedad, tanto griegos como romanos, no conciben el trabajo como positividad, antes bien, lo sienten como negatividad; no lo entienden como algo que, siendo expresión del hombre, le define en su dignidad y le ensalce como valor, sino a modo de peso que abruma o de fatiga que deprime. Expone también al respecto que el propio Homero, que con tanta complacencia admira a los dioses, reflejando en ellos todos los deseos humanos, los canta sublimes e inmunes al trabajo, así como que serán pendencieros y agitados por todas las pasiones humanas, traidores y adúlteros, amantes y envidiosos, pero nunca trabajadores; desde lo alto de Eliseo contemplan la vida o se entregan prácticamente a ella, a veces siendo partícipes de las mismas vicisitudes humanas, y salvo rarísimas excepciones (el caso de Vulcano), aparecen liberados del trabajo; y tanto es así, que no solo se codicia como divina una condición sin la carga del trabajo, sino que se

${ }^{1}$ Respecto al significado del concepto de trabajo en la actualidad, en sus aspectos sociales y jurídicos, así como para una aproximación a la formación históricojurídica del denominado Derecho del Trabajo, Vid. Alonso García, M., Curso de Derecho del Trabajo, Edit. Ariel, Barcelona, 1981, págs. 4 y ss. A su vez, en relación a la realidad social actual que subyace al Derecho del Trabajo y a sus derivaciones más próximas, así como para otras cuestiones relativas a sus características y la regulación del mismo, Vid. Alonso Olea, M., Casas Baamonde, M. ${ }^{a}$.E., Derecho del Trabajo, Edit. Civitas Ediciones, Madrid, 2000, pág. 39 y ss.

2 Battaglia, F., Filosofia del lavoro, Edit. Dott. Cesare Zuffi Editore, Bolonia, 1951, págs. 15-16. 
afirma explícitamente que odian a los hombres ${ }^{3}$, hasta el punto de aparecer la actividad laboral como consecuencia de este odio. A su vez, afirma que la institución de la esclavitud se explica, bien por las particularidades económicas de la antigüedad, bien en relación a tal concepción del trabajo indicada.

Entre los pensadores y filósofos de la Grecia antigua se aprecian dos posiciones diferentes acerca del fenómeno del trabajo, una negativa y otra más positiva, las cuales conviven juntas. Estas posiciones parten de dividir el trabajo en dos clases: el manual y el intelectual. La visión negativa del trabajo - que es la que predomina- se apoya, de manera implícita, en el hecho de la existencia de la esclavitud. De un lado, existe una visión negativa del trabajo manual — que será la que prevalezca - por su consideración de actividad que debe desempeñar la gente inculta, socialmente no considerada, y los esclavos, así como por ser indigno para el hombre libre y ciudadano, provisto de educación y cultura, cuyos quehaceres deben ir encaminados al gobierno de la polis. El hombre libre y ciudadano debía dedicarse a perfeccionar la posesión y el uso del logos, es decir, a perfeccionar la palabra y el lenguaje - no la mano-, con el fin último de poder intervenir de manera eficaz en los asuntos políticos ${ }^{4}$.

En tal sentido, Jenofonte sostiene que el trabajo es la retribución del dolor por el que los dioses venden los bienes ${ }^{5}$. A su vez, este pensador entiende que el trabajo debilita el físico y el ánimo de los que lo ejecutan y dirigen, impidiéndoles ejercitar la amistad y sus deberes ciudadanos ${ }^{6}$. De igual manera, Platón ${ }^{7}$ elimina a las artes mecánicas del gobierno del Estado, del ejercicio de los

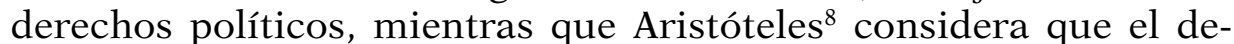
sempeño de trabajos manuales, mercantiles o agrícolas representan formas de vida innobles y contrarias a la virtud. Para Platón, tanto los que trabajaban manualmente, como, en general, los que ejercitan actividades económicas para conseguir un lucro - a los

${ }^{3}$ Homero, Ilíada, traducción de López Eire, A., Edit. Civitas, Madrid, 2005, XVIII,104, pág. 16.

${ }^{4}$ Rodríguez Montero, R.P., Notas introductorias en torno a las relaciones laborales en Roma, en Anuario da Facultade de Dereito da Universidade da Coruña, N. ${ }^{\circ}$, «A Coruña», 2004, pág. 728.

${ }^{5}$ Battaglia, F., Filisofia del lavoro, op. cit., pág. 16; en nota a pie de página, Jenof. Mem.II,1.

${ }^{6}$ Lana, I., Sapere, lavoro e potere in Roma antica, Edit. Jovene, Napoles, 1990, pág. 401; en nota a pie de página, Jenof. Econ.IV.2-3.

7 Platón, República, en República. Parménides. Teeteto, Tomo II, traducción de EgGers Lan, C., Edit. Gredos, Madrid, 2011, Rep. III,415, págs. 115-116.

8 Aristóteles, Política, en Ética Nicomáquea. Política, Tomo III, traducción de García Valdes, M., Edit. Gredos, Madrid, 2011, Pol. VII,1328b, págs. 520-521. 
que considera con alma de esclavo e inconvenientes para participar en el gobierno de la ciudad- deben ser excluidos del goce de los derechos ciudadanos ${ }^{9}$. Aristóteles considera que, el trabajo, en sí mismo, no presenta una dignidad específica, ni un valor autónomo, y recomienda practicarlo, tan sólo, para poder obtener ganancias y vivir después libre del mismo, es decir, como un medio a través del cual se pueda subsistir e incluso llegar a hacer fortuna, precisamente al objeto de no trabajar y poder conseguir el fin último de todo hombre, que, según este pensador, consiste en la posesión de la virtud ${ }^{10}$. Según este pensador, el Estado que tiene la mejor constitución, es aquél en el que sus ciudadanos no son ni operarios ni comerciantes, y ni siquiera agricultores, porque, en el caso de los primeros, sostiene que su género de vida es contrario a la virtud, y, en el de los segundos, considera que les falta tiempo libre suficiente para poder dedicarlo a la virtud y a la política ${ }^{11}$.

Por otro lado, en cuanto a la visión más positiva del trabajo manual - que no triunfaría-, es la mantenida por pensadores como Hesíodo, Solón e Hipias. Estos autores mantienen la valoración del trabajo y la fatiga como instrumentos para alcanzar el bienestar y, desde la perspectiva prevalente del trabajo agrícola, como medio para la lograr la autarquía, entendida como autosuficiencia. Hipias proclama su autosuficiencia mostrándose hábil en el trabajo manual, al valorar positivamente no sólo la posesión de la palabra y del lenguaje - $\operatorname{logo}$ - sino otras muy diversas técnicas manuales, como las del tejedor, del herrero, del zapatero, etc. ${ }^{12}$. En el mismo sentido se pronuncia Anaxágoras quien opina que la supremacía del hombre sobre los demás animales tiene su fundamento esencial en que aquél posee la mano, motivo por el que es más inteligente que el resto ${ }^{13}$.

\section{PROYECCIÓN DE LAS CONCEPCIONES GRIEGAS EN ROMA}

En la Roma antigua, la consideración del trabajo presenta grandes similitudes con la visión griega al respecto. Como bien afirma

${ }^{9}$ LANA, I., Sapere, lavoro e potere in Roma antica, op. cit., pág. 401; en nota a pie de página, Plat. Rep.III,415, Plat. Gorg.512, Plat. Pol.289-290, Plat. Alcib.Prim.131 y Plat. Ley.846.

${ }^{10}$ Lana, I., Sapere, lavoro e potere in Roma antica, op. cit., pág. 402; en nota a pie de página, Arist. Pol.VII,1333a-b.

11 Ibidem; en nota a pie de página, Arist. Pol.VII, 1328a-b.

12 Lana, I., Sapere, lavoro e potere in Roma antica, op. cit., pág. 400; en nota a pie de página, Plat. Hip.Men.386b-e.

13 Ibidem; en nota a pie de página, D. - K 59 A 102. 
Rodríguez Montero ${ }^{14}$, en el mundo romano existe una clara dicotomía entre la concepción social del trabajo, dominante en la mentalidad corriente, y la visión filosófica del mismo, en la que, junto a la lingua, se exaltan las artes y el trabajo de la manus, y que se asienta en una estimación antropocéntrica de la realidad, según la cual todo lo que se encuentra en el universo, y este mismo, existe para y en función de los dioses y los hombres.

En lo que respecta a la concepción social del trabajo, su análisis debe tomar como punto de partida el parámetro relativo al decorum, que está en estrecha relación con el relativo a la dignitas. La sociedad romana se estructura, de manera básica, en hombres libres y cives -sui iuris y alieni iuris-, libertos y esclavos ${ }^{15}$. El ciudadano libre y de pleno derecho - sui iuris - tiene como máxima aspiración el desempeño determinadas funciones dentro de la comunidad, representando alto grado de relevancia las relativas a los puestos más elevados del cursus honorum o carrera magistral, para los que, junto a otras condiciones, resulta imprescindible poseer la dignitas necesaria, que aparece ligada al decorum, es decir, a lo que resulta conveniente para quien aspira a ocupar las más altas magistraturas. La dignitas se obtiene, principalmente, a través de la utilización eficaz de la palabra en interés de los asuntos públicos. Así, la actividad oratoria se erige en la más deseada y estimada por los romanos, por entenderla, entre todas las posibles, como la más idónea para el decorum del cives. En definitiva, todo aquello que no tenga relación alguna con las técnicas del dominio de la palabra resulta para la sociedad romana negativo o nocivo, e incluso indiferente ${ }^{16}$.

Cicerón, en su obra De Officiis, estructura jerárquicamente las actividades de trabajo y de producción de bienes y servicios en función de aquellas que se muestran, conforme al decoro, acordes a un ciudadano libre; es decir, cuales son convenientes y decentes, para distinguir estas de aquellas que considera viles y deshonrosas.

En De offic. 1,40,151 ${ }^{17}$, consiente que el hombre libre, aparte de su dedicación al foro y a la milicia, pueda consagrarse a la agricultura

${ }^{14}$ Rodríguez Montero, R.P., Notas introductorias en torno a las relaciones laborales en Roma, op. cit., pág. 729.

15 García Garrido, M.J., Derecho Privado Romano. Casos-acciones-instituciones, Edit. Ediciones Académicas, Madrid, 2015, pág. 51.

${ }^{16}$ Rodríguez Montero, R.P, Notas introductorias en torno a las relaciones laborales en Roma, op. cit., pág. 730.

${ }_{17}$ Cic. De Offic. 1,42,151: [...] Quibus autem artibus aut prudentia maior inest aut non mediocris utilitas quaeritur ut medicina, ut architectura, ut doctrina rerum honestarum, eae sunt iis, quorum ordini conveniunt, honestae. Mercatura autem, si te- 
- referida al dominio y la dirección de los fundos agrícolas- y al «comercio al por mayor». Asimismo, de manera previa, en el mismo fragmento, recoge todas aquellas profesiones que requieren un mayor saber y que reportan mayor utilidad a la comunidad, las cuales se corresponden con la medicina, la arquitectura y la enseñanza de las "artes liberales», respecto de las que entiende que pueden ser desempeñadas con honor sólo por ciudadanos romanos libres con la condición social adecuada.

En sentido contrario, en De Offic. $1,42,150^{18}$, hace constar que todas las otras actividades son viles y deshonrosas, desde la que realiza el pequeño comerciante a las "artes mecánicas», desde el jornal a la usura, porque dice que las mismas hacen dependiente y subordinan al hombre libre, bien de otros hombres, bien de las ganancias. Por tanto, Cicerón alude, aparte de a los recaudadores de impuestos y los prestamistas de dinero con interés, a todos aquellos que ejecutan actividades que actualmente calificaríamos como de trabajo dependiente, los denominados mercennarius, es decir, los que reciben una merced por prestar su fuerza de trabajo, a modo de precio por servidumbre. A la par, coloca en el mismo plano que estos a los pequeños comerciantes, como ya se ha expuesto, a los artesanos, y a aquellos otros que, en general, proveen los lujos y los placeres, tales como los cocineros, bailarines, perfumistas, pescaderos, carniceros, etc.

Así, para Cicerón, las actividades manuales o derivadas del trabajo dependiente o subordinado se consideran viles, deshonestas, sórdidas e, incluso, iliberales; se consideran impropias de un

\footnotetext{
nuis est, sordida putanda est; sin magna et copiosa, multa undique apportans multisque sine vanitate inpertiens, non est admodum vituperanda; atque etiam si satiata quaestu vel contenta potius, ut saepe ex alto in portum, ex ipso se portu in agros possessionesque contulit, videtur iure optimo posse laudari. Omnium autem rerum, ex quibus aliquid adquiritur, nihil est agri cultura melius, nihil uberius, nihil dulcius, nihil homine libero dignius. De qua quoniam in Catone Maiore satis multa diximus, illim assumes quae ad hunc locum pertinebunt [...]

18 Cic. De Offic.1,42,150: [...] Iam de artificiis et quaestibus, qui liberales habendi, qui sordidi sint, hace fere accepimus. Primur improbantur ii quaestus, qui in odia hominum incurrunt, ut portitorum, ut feneratorum. Iliberales autem et sordidi quaestus mercennariorum omnium, quorum operae, non quorum artes emuntur; est enim in illis ipsa merces auctoramentum servitutis. Sordidi etiam putandi, qui mercantur a mercatoribus, quod statim vendant; nihil enim proficiant, nisi admodum mentiantur; nec vero est quicquam turpius vanitate. Opificesque omnes in sordida arte versantur; nec enim quicquam ingenuum habere potest officina. Minimeque artes eae probandae, quae ministrae sunt voluptatum: Cetarii, lanii, coqui, fartores, piscatores, ut ait Terentius; adde huc, si placet, unguentarios, saltatores, totumque ludum talarium [...]
}

(c) UNED. Revista de Derecho UNED, núm. 24, 2019 
hombre libre ${ }^{19}$. En el mundo romano antiguo -al igual que en el griego- la situación ideal del hombre se subsume dentro del otium, entendido como un estado productivo, dedicado a ensalzar y cultivar la mente y el cuerpo, en contemplación del mundo.

Además, hay otro factor relevante en orden a determinar el por qué del desprecio de los romanos hacia el trabajo manual, retribuido a través de la merces o renta, que no es otro que la existencia de la esclavitud y su especial consideración dentro de la estructura económica de mundo romano. Es comúnmente admitido que los primeros acuerdos en los que aparece como finalidad la prestación de energías de trabajo se configura como una cesión temporal, por parte del dominus, de un esclavo propio para que el cesionario se beneficiase de la actividad laboral del mismo, a cambio del pago de un precio determinado. Así, es comúnmente admitido que el esclavo tiene la consideración jurídica de una cosa más en propiedad de su dueño, por lo que tal cesión temporal en nada puede diferenciarse de la locatio rei ${ }^{20}$. Como mantiene Gómez-Iglesias Casal, el objeto del contrato es la persona del trabajador y no su trabajo ${ }^{21}$. Por tanto, desde un principio, los trabajos denominados por Cicerón como deshonestos o deshonrosos, especialmente los manuales y los que requieren imprimir esfuerzo físico en su ejecución, son realizados por esclavos.

Pero, ya desde la época clásica se plantea el problema de que ese tipo de trabajos, considerados como serviles, pasan a ser desempeñados por ciudadanos libres, práctica que se consolida en época postclásica $^{22}$. Sus causas se remontan a la época Republicana, ya que es en ella, dada la extensión de las fronteras romanas por las guerras de conquista, cuando se produce la evolución y el cambio de una economía agrícola y pastoril a la economía mercantil de la Roma-mercado ${ }^{23}$. Dicha expansión económica tiene su evidente re-

${ }^{19}$ En el mismo sentido, Séneca, en Epistolae ad Lucicilium (Ad. Luc. XIV,90,19), sostiene que las actividades mecánicas son cosas de esclavos, no para hombres libres.

${ }^{20}$ De Robertis, F., I rapporti di lavoro nel Diritto Romano, Edit. Dott. A. Giuffrè Editore, Milano, 1946, pág. 123; y MarTini R., Mercennarius. Contributo allo studio dei rapporti di lavoro in Diritto Romano, Edit. Dott. A. Giuffrè Editore, Milano, 1958, págs. 15 y ss. Ambos autores defienden el origen de la locatio conductio operarum, o trabajo subordinado de persona libre, en la locatio servi.

${ }_{21}$ Gómez-Iglesias Casal, A., La influencia del Derecho Romano en las modernas relaciones de trabajo, op. cit., pág. 30 .

${ }^{22}$ Gómez-Iglesias Casal, A., La influencia del Derecho Romano en las modernas relaciones de trabajo, op. cit., pág. 37 .

${ }^{23}$ Flores Robles, C., García Garrido, M.J., Jongitud Zamora, J., Márouez GonZÁlez, J.A., Moncayo Rodríguez, S., Transformaciones jurídicas en el contexto de la globalización. Contratos: Tradición y globalización, Vol. II, Edit.Arana Editores, Xalapa (México), 2007, págs. 40-41. 
flejo en la necesidad de mano de obra y, por tanto, en la dedicación de ciudadanos libres a labores artesanales y otras similares a estas, en las que se precisa de cierta cualificación.

Los hombres libres realizan el trabajo subordinado y el mecánico a través de las modalidades de la locatio conductio operarum y la locatio conductio operis ${ }^{24}$. En la primera de ellas, la obligación del trabajador se fundamenta en un dare, divisible y personalísima, que es recompensado con una merces, en función del tiempo trabajado (retribución a jornal), o en la medida de las unidades de trabajo efectivamente ejecutadas (retribución a destajo). En la segunda, en la que la obligación del trabajador es de facere, indivisible y con la posibilidad de valerse de terceras personas, la retribución se debe en la medida en que aquél haya entregado el producto final acabado ${ }^{25}$.

Los trabajos de menor consideración social realizados por hombres libres, que prácticamente no requerían cualificación alguna, tenían su origen, por lo general, en la relación contractual de la locatio-conductio operarum. A los trabajadores que colocaban su persona o fuerza de trabajo a favor de otros eran a los que se les denomina mercennarius ${ }^{26}$. Se les atribuye tal nombre por el hecho de ser recompensados por el trabajo realizado a través de una merces.

Siguiendo a Gómez-Iglesias Casal27, la denominación de mercennarius puede ser utilizada en un sentido amplio o en un sentido restringido. En el sentido amplio, o genérico, se refiere a todas aquellas personas que reciben una merces por la realización de su trabajo. En un sentido más restringido, o estricto, designa sólo aquellos trabajadores que no desempeñan una actividad concreta o especializada, que no practican un ars. A su vez, dicho autor, en lo que respecta al mercennarius, sostiene «El sentido peyorativo del término, basado en el desprecio social hacia el trabajo libre remunerado, hace que

${ }^{24}$ De Robertis, F, I rapporti di lavoro nel Diritto Romano, op. cit., págs. 121 y ss. De otra parte, en cuanto a la concepción unitaria de la locatio conductio, Vid. FerNández De Buján, F., Sistema contractual romano, Edit. Dykinson, Madrid, 2004, pág. 265; y Gómez-Iglesias CASAL, A., La influencia del Derecho Romano en las modernas relaciones de trabajo, op. cit., págs. 43-44.

${ }_{25}$ Gómez-Iglesias Casal, A., La influencia del Derecho Romano en las modernas relaciones de trabajo, op. cit., pág. 60; y GARcía GARRIDO, M.J., Derecho Privado Romano. Casos-acciones-instituciones, op. cit., pág 214.

${ }^{26}$ Gómez-Iglesias Casal, A., La influencia del Derecho Romano en las modernas relaciones de trabajo, op. cit., pág. 48.

27 Gómez-Iglesias C asal, A., La influencia del Derecho Romano en las modernas relaciones de trabajo, op. cit., pág. 49.

(C) UNED. Revista de Derecho UNED, núm. 24, 2019 
frecuentemente se le utilice en el sentido más restringido de los que hemos visto». El autor, por tanto, entiende que existe una contraposición entre lo que abarca la expresión mercennarius en sentido estricto y la realidad que engloba dicho término en sentido lato; ello obliga a deducir que, en la Roma antigua, existen diferencias, tanto sociales como jurídicas, entre los distintos tipos de trabajadores. En definitiva, el que tiene una consideración social más baja es el mercennarius en sentido estricto, por carecer de especialización alguna. El mercennarius en sentido amplio tiene una mayor consideración social, dado que domina ciertas técnicas de un oficio o practica un ars. Para este autor, el mercennarius es un trabajador libre que realiza los trabajos más indignos, los que tienen una consideración social más baja, puesto que, en un principio, solían ser desempeñados por esclavos ${ }^{28}$.

${ }^{28}$ Otra cuestión importante, relativa al trabajador mercenario, es la que se refiere a su situación jurídica. Para De Robertis, aunque el trabajador mercenario no pierde su status libertatis, la jurisprudencia clásica considera que éste se encuentra entre las personas loco servorum; lo que deduce de los textos que asimilan al trabajador que nos ocupa al esclavo o al liberto que está en la casa del dominus, por lo que también pasa a formar parte de la familia del arrendatario, así como a estar sometido a su potestad disciplinaria. Por el contrario, para Martini, la situación del trabajador mercenario es de una mera posición de subordinación frente al conductor, no de sometimiento cuasi-total. Para este último autor, la posición del mercennarius no era tan indigna y es, precisamente, la diferencia jurídica de no encontrarse totalmente sometido al conductor lo que distingue a estos trabajadores de los esclavos. Gómez-Iglesias Casal opina que no parece admisible pensar en la existencia de una figura contractual en la cual la posición de una persona libre se considere asimilada a la situación jurídica de la esclavitud. Sin embargo, el mismo autor aduce, en contra de la referida posición de Martini, que el intento de dignificar la situación del mercennarius no puede ser tan aceptable; de una parte, entiende que no basta aludir a los textos jurisprudenciales para demostrar que en Derecho clásico el trabajo manual y remunerado goce de una alta consideración, ya que, en su opinión, el término mercennarius no es estrictamente técnico, sino que es utilizado en el lenguaje vulgar, y, de otra parte, apunta que no es improbable que la carga peyorativa del término mercennarius tenga un origen militar y haga referencia a los soldados que se ofrecen al servicio de un país extranjero a cambio de un precio por su actuación. Gomez-Iglesias Casal explica que "para establecer una consideración sociológica, como sería la ínfima consideración social o la despreciable situación del mercennarius, no es suficiente apelar únicamente a su situación jurídica», para continuar afirmando que en las relaciones sociales «no se clasifica o etiqueta a las personas sólo por el tipo de contrato por el que ceden su trabajo que se desconocería, incluso, en la mayoría de los casos - , sino también por su apariencia exterior, por la situación social fáctica». Vid. DE RoBerTIS, F., I rapporti di lavoro nel Diritto Romano, op. cit., págs. 130 y ss.; MARTINI, R., Mercenarius. Contributo allo studio dei rapporti di lavoro in Diritto Romano, op. cit., 50 y ss.; y Gómez-Iglesias CASAL, A., La influencia del Derecho Romano en las modernas relaciones de trabajo, op. cit., págs. 54-55. 


\section{LAS PROFESIONES LIBERALES EN EL MUNDO ROMANO ANTIGUO}

\section{III.A. Ulpiano y la reclamación de los honorarios}

Para entrar a analizar las características esenciales, tanto sociales como jurídicas, de lo que en la Roma antigua se conoce como operae liberales, nos centraremos en un texto fundamental al respecto, insertado en el Título XIII del Libro L del Digesto, que lleva por rúbrica de variis et extraordinem cognitibus et si iudex litem suam fecisse dicetur ${ }^{29}$, y que incluye un fragmento, del jurista Ulpiano, en el que se plantean diversos supuestos de prestación de servicios ejecutados por los que se dedican a este tipo de profesiones.

El fragmento ulpianeo que nos ocupa, con origen en el Libro VIII de su obra De omnibus tribunalibus, y recogido en D.50,13,1, que proporciona información fundamental para el tema objeto del presente análisis, y que parece asimilar y equiparar a todas las actividades libres e independientes con las del ámbito de lo que más estrictamente designa como studia liberales (gramática, retórica o arquitectura), excluye a las mismas de la locatio conductio y de su régimen procesal, de lo que se deduce, ya, de la mera observación directa de la rúbrica del propio Título, que las reclamaciones retributivas relativas al desempeño de la profesión liberal de que se trate deben efectuarse a través de la cognitio extraordinem. Del texto ulpianeo se infieren las siguientes profesiones liberales $^{30}$ : a) La de los que enseñan o praeceptores studiorum liberalium, es decir, los maestros de gramática y literatura, y los de elocuencia o retores, así como los maestros de matemáticas o geometrae, los maestros de escuela o iudi magistri y los librarii, los notarii y los caculatore tabularii, b) los médicos, tanto los que practican la medicina general como los especialistas, categoría en la que deben incluirse a las parteras y a las nodrizas; c) los abogados; d) los profesores de Derecho Civil.; e) los filósofos; f) y los agrimensores.

${ }^{29}$ Gómez-Iglesias Casal, A., La influencia del Derecho Romano en las modernas relaciones de trabajo, op. cit., pág. 50 .

${ }^{30}$ Camacho Evangelista, F., Las profesiones liberales en Roma, Edit. Publicaciones de la Ecuala Social de Granada, Granada, 1963, pág. 10. 


\section{III.B. Referencia a las distintas profesiones liberales}

\section{III.B.1. Praeceptores studiorum liberalium}

En D.50,13,1pr., en relación con los retóricos y gramáticos, Ulpiano refiere que el gobernador de la provincia es el competente para juzgar sobre los salarios, pero tan sólo de los que se deben a los preceptores de estudios liberales. El jurista entiende por studia liberales los que los griegos llaman eleutheria (libres), que abarcan los retóricos, los gramáticos y los de agrimensura.

D.50,13,1pr. Ulpianus libro octavo de omnibus tribunalibus.

[...] Praeses provinciae de mercedibus ius dicere solet, sed praeceptoribus tantum studiorum liberalium. liberalia autem studia accipimus, quae Graeci leuqšria appellant: rhetores continebuntur, grammatici, geometrae [...]

En otro pasaje del mismo fragmento, en relación a los maestros de letras, establece que, aunque éstos puedan ser considerados profesores, es un uso corriente que también juzgue el gobernador de la provincia sobre su salario, así como sobre el de los copistas de libros, escribanos, contadores y archiveros.

D.50,13,1,6 Ulpianus libro octavo de omnibus tribunalibus.

[...] Ludi quoque litterarii magistris licet non sint professores, tamen usurpatum est, ut his quoque ius dicatur: iam et librariis et notariis et calculatoribus sive tabulariis [...]

Camacho Evangelista ${ }^{31}$ señala que los gramáticos enseñan literatura a los adolescentes, estudios que pueden ser considerados como de segundo grado. La retórica se eleva a un grado de enseñanza superior $^{32}$ y, como afirma Agudo Ruiz ${ }^{33}$, presupone una formación previa en gramática y en poesía, una capacidad teórica y práctica desarrollada gracias a la lectura, comentario e imitación de los buenos poetas.

El ciudadano romano libre tiene como máxima aspiración el desempeño de determinadas funciones dentro de la comunidad, con prioridad absoluta sobre las de mayor relevancia social, que son las relativas a los puestos más elevados del cursus honorum o carrera magistral, para lo que, junto a otras condiciones, resulta imprescin-

31 Camacho Evangelista, F., Las profesiones liberales en Roma, op. cit., pág. 12.

32 De León Lázaro, G., La educación en Roma, en Anuario Jurídico y Económico Escurialense, XLVI, Madrid, 2013, págs. 478-480.

33 Agudo Ruiz, A., Abogacía y abogados, un estudio histórico-jurídico, Edit. Egido Editorial, Zaragoza, 1997, págs. 40-41. 
dible poseer la dignitas necesaria, la cual aparece ligada al decorum, es decir, a lo que resulta conveniente para quien aspira a ocupar las más altas magistraturas. La dignitas es obtenida en la Roma antigua, primordialmente, a través de la utilización eficaz de la palabra en interés de los asuntos públicos. Por ello, desde la edad más temprana de su juventud, el ciudadano romano libre, que pertenece a la aristocracia, se forma en el buen uso de la palabra, así como en el dominio de la elocuencia.

Para adquirir los conocimientos adecuados al respecto, la clase dominante se vale de los servicios prestados por los profesores de gramática y los de retórica, que pueden desempeñar su labor tanto desde el plano privado como público. En época Republicana, aun existiendo profesores de retórica que son contratados por algunas ciudades (incluso con financiación en parte privada y en parte pública), predomina la educación de iniciativa privada. Así los profesores son contratados por los padres de familia para que impartan sabiduría y conocimientos a sus hijos.

En lo que respecta al ámbito público, a comienzos de la época imperial, surge en Roma una política educativa de iniciativa y patrocinio estatal, por medio de un fuerte intervencionismo de los emperadores, quienes, a tal fin, habilitan espacios públicos en los que los docentes puedan desempeñar en óptimas condiciones su oficio, se preocupan de asegurar la regularidad de los salarios de éstos, que se detraen del erario público y, por lo tanto, no son abonados por los padres, y, por último, les otorgan una serie de privilegios personales y fiscales. A su vez, incluso los emperadores se preocupan de dotar a la metrópoli romana y a las ciudades más importantes de bibliotecas públicas, como una muestra más de su especial interés por la educación y la cultura ${ }^{34}$.

Así, es evidente que, en época imperial, los preceptores que dependen del Estado tienen menos problemas para ser recompensados por los servicios prestados. Todo lo contrario, sucede a los profesores que imparten clase en ámbito privado, los cuales encuentran numerosos obstáculos para el cobro de sus honorarios ${ }^{35}$.

${ }^{34}$ En lo que respecta a la enseñanza superior en los períodos Republicano, Imperial y Justinianeo, Vid. Agudo RuIz, A., Abogacía y abogados, un estudio histórico jurídico, op. cit., págs. 25-54 y págs. 56-91.

35 Suetonio, en su obra De Grammaticis, informa que los malos pagadores hacen legión entre sus clientes. Sue.Gramm.,9: [...] L. Orbilius Pupillus Beneventanus, morte parentum, una atque eadem die inimicorum dolo interemptorum, destitutus, primo apparituram magistratibus fecit; deinde in Macedonia corniculo, mox equo meruit; functusque militia, studia repetit, quae iam inde a puero non leviter attigerat; ac professus diu in patria, quinquagesimo demum anno Romam consule Cicerone tran-

(C) UNED. Revista de Derecho UNED, núm. 24, 2019 
III.B.2. Advocati

En lo que respecta a los abogados, Ulpiano les dedica una extensión más amplia que al resto. Ello responde a que los abogados constituyen, como afirma Camacho Evangelista ${ }^{36}$, un problema social más complejo y, al punto, un elemento vital en el mundo romano antiguo, por lo que el tema debe ser planteado en consonancia con la especial importancia que adquieren los titulares de esta profesión en tal contexto histórico.

En D.50,13,1,10, Ulpiano, en lo que respecta a los honorarios de los abogados, expone un rescripto dictado por los emperadores Caracala y Septimio Severo, conforme al que, para estimarlos, el juez debe tener en cuenta «la importancia del litigio y la facundia del abogado, según lo acostumbrado en el foro, siempre que la cuantía no exceda de lo que es un honorario lícito».

D.50,13,1,10 Ulpianus libro octavo de omnibus tribunalibus.

[...] In honorariis advocatorum ita versari iudex debet, ut pro modo litis proque advocati facundia et fori consuetudine et iudicii, in quo erat acturus, aestimationem adhibeat, dummodo licitum honorarium quantitas non egrediatur: ita enim rescripto imperatoris nostri et patris eius continetur. verba rescripti ita se habent: «Si Iulius Maternus, quem patronum causae tuae esse voluisti, fidem susceptam exhibere paratus est, eam dumtaxat pecuniam, quae modum legitimum egressa est, repetere debes» $[\ldots]$

En el fragmento siguiente, el jurista define lo que debe entenderse por abogado. Para ello, se centra en determinar quienes deben tener esta condición, que identifica con los que se dedican a la defensa de las causas judiciales, para diferenciarlos de los que no

siit docuitque maiore fama quam emolumento. Namque iam persenex pauperem se et habitare sub tegulis quodam scripto fatetur. Librum etiam, cui est titulus Perialogos, edidit continentem querelas de iniuriis, quas professores neglegentia aut ambitione parentum acciperent. Fuit antem naturae acerbae, non modo in antisophistas, quos omni in occasione laceravit, sed etiam in discipulos, ut et Horatius significat plagosum eum appellans, et Domitius Marsus scribens: Si quos Orbilius ferula scuticaque cecidit [...] Ac ne principum quidem virorum insectatione abstinuit; siquidem ignotus adhuc cum iudicio frequenti testimonium diceret, interrogatus a Varrone diversae partis advocato, quidnam ageret et quo artificio uteretur, gibberosos se de sole in umbram transferre respondit; quod Murena gibber erat. Vixit prope ad centesimum aetatis annum, amissa iam pridem memoria, ut versus Bibaculi docet: Orbilius ubinam est, litterarum oblivio? [...] Statua eius Beneventi ostenditur in Capitolio ad sinistram latus marmorea habitu sedentis ac palliati, appositis duobus scriniis. Reliquit filium Orbilium, et ipsum grammaticum professorem [...]

${ }^{36}$ Camacho Evangelista, F., Las profesiones liberales en Roma, op. cit., pág. 18. 
deben incluirse en la categoría, como aquellos que cobran por una mera consulta sin intervenir en un litigio.

\section{D.50.13,1,11 Ulpianus libro octavo de omnibus tribunalibus.}

[...] Advocatos accipere debemus omnes omnino, qui causis agendis quoque studio operantur: non tamen qui pro tractatu, non adfuturi causis, accipere quid solent, advocatorum numero erunt [...]

Existen diferencias sustanciales entre el jurisconsulto y el abogado o el profesional del derecho en general. Jurisprudente es el que realiza la labor propia de consulentes públicos o privados. No se trata de un abogado, ni de un profesional del derecho; no perora por sus clientes, ni persuade a los jueces por medio de las técnicas y tácticas de la retórica, ni se presenta ante los tribunales para desarrollar las pruebas y realizar el examen de testigos, ni acompaña a un cliente y le ayuda en el proceso, funciones que son propias del orador o abogado ${ }^{37}$. Se ocupan de aconsejar a los que requieren de su saber sobre las fórmulas, instituciones o reglas jurídicas más adecuadas para el negocio o el pleito que someten a su estudio. Al jurisconsulto romano le preocupan sólo aquellas reglas, claras, precisas y sencillas, que sirven para resolver los problemas de la vida cotidiana. Estos juristas son ciudadanos de clase noble, que, en su propia casa, o en el foro, responden a las preguntas de todos aquellos que tienen la necesidad de su consejo, así como asesoran, también, sobre negocios privados ${ }^{38}$.

37 Aunque a los abogados se les reconoce el buen conocimiento del Derecho, nunca se les exige tal condición. No es impropio ni indigno, sino más bien conveniente, que el abogado acuda al jurisconsulto antes de iniciar la causa, a fin de que le facilite y suministre las armas para una defensa segura, hasta vel tela subministrare. Durante el dominado, tras la fusión entre las figuras del abogado y jurisconsulto, la situación cambia, al deber acreditar aquél la certificación de la obtención de los conocimientos jurídicvos y técnicos necesarios para la práctica forense, sobre todo después de constituirse las escuelas oficiales de Derecho. Vid. Rossi, R., Observaciones sobre la figura del abogado en Derecho Romano, en Studi in onore di Giuseppe Grosso, Vol. I, Edit. G. Diapidreli, Torino, 1970, págs. 276-280.

${ }_{38}$ Como nos informa Cicerón en su obra De Oratore. De orat. 1,11,45: [...] Tum ille «non sum» inquit "nescius, Scaevola, ista inter Graecos dici et disceptari solere; audivi enim summos homines, cum quaestor ex Macedonia venissem Athenas, florente Academia, ut temporibus illis ferebatur, cum eam Charmadas et Clitomachus et Aeschines obtinebant; erat etiam Metrodorus, qui cum illis una ipsum illum Carneadem diligentius audierat, hominem omnium in dicendo, ut ferebant, acerrimum et copiosissimum; vigebatque auditor Panaeti illius tui Mnesarchus et Peripatetici Critolai Diodorus [...] De orat. 3,33,133: [...] Equidem saepe hoc audivi de patre et de socero meo, nostros quoque homines, qui excellere sapientiae gloria vellent, omnia, quae quidem tum haec civitas nosset, solitos esse complecti. Meminerant illi Sex. Aelium; $M$ '. vero Manilium nos etiam vidimus transverso ambulantem foro; quod erat insigne eum, qui id faceret, facere civibus suis omnibus consili sui copiam; ad quos olim et ita ambulantis et in solio sedentis domi sic adibatur, non solum ut de iure civili ad eos,

(C) UNED. Revista de Derecho UNED, núm. 24, 2019 
A la labor de interpretación que llevan a cabo estos prudentes, de prestrar consejo mediante sus responsa sobre las reglas jurídicas, las fórmulas o las instituciones y documentos adecuados para la más práctica solución de un supuesto concreto de hecho, se le denomina jurisprudencia. Esto es la prudentia iuris, el arte de saber elegir. En palabras de García Garrido ${ }^{39}$ "este arte de la prudencia no es una vacía aspiración moral, sino que constituye el trasplante al derecho de aquel proceder recto y de la firme actitud que, como virtud humana, rige los azares de la vida y constituye el más rico patrimonio de paterfamilias».

Por medio de los responsa contestan a las consultas que se les hacen sobre casos reales y debatidos, dotando sus opiniones de toda clase de datos y circunstancias que califican especialmente la cuestión tratada y reafirmando sus argumentos con opiniones de juristas precedentes. De la rica casuística que resulta de sus responsa, abstraen, con suma cautela, principios comunes y generales, pero sin perder nunca de vista la finalidad práctica originaria, así como les sirve de medio técnico favorecedor y simplificador de nuevas decisiones. Puede decirse que el método habitual de los juristas es el inductivo. El agere consiste en la dirección del proceso o procedimiento, dando a la parte una nota escrita de la legis actio o fórmula, o acompañándola ante el magistrado y sugiriendo las palabras a pronunciar o los actos a cumplir. Mediante el cavere los juristas intervienen en la vida y el tráfico jurídico, señalando la línea de actuación para evitar perjuicios a las partes, dando respuesta a las necesidades económicas y sociales con la provisión de nuevos medios cada vez más abiertos.

Pero, a su vez, los juristas son creadores e innovadores del Derecho. La principal fuente integradora del Derecho la constituyen sus decisiones y respuestas, por lo que son denominados iuris auctores o iuris conditores. Su actividad se desenvuelve mediante un continuo proceso de elaboración que se denominaba interpre-

verum etiam de filia conlocanda, de fundo emendo, de agro colendo, de omni denique aut officio aut negotio referretur $[$...]

39 García GarRido, M.J., Derecho Privado Romano. Casos-acciones-instituciones, op. cit., págs. 19-46. El autor pormnoriza en las características de la jurisprudencia romana en sus distintas épocas, así como indica las diferencias entre orator y jurisprudente. También, sobre las distintas épocas en la jurisprudencia romana, Vid. García Garrido, M.J., Fernández De Buján, F., Fundamentos clásicos de la democracia y de la administración, Edit. Ediciones Académicas, Madrid, 2010, págs. 248253. Las diferencias entre jurisconsulto y abogado desaparecen con la implantación definitiva, como único proceso, del procedimiento cognitorio, Vid. GARCía GarRIDO, M.J., Casuismo y Jurisprudencia Romana (Responsa). II. Acciones y casos, Vol. II, Edit. Ediciones Académicas, Madrid, 2008, págs. 86-97. 
tatio $^{40}$, como integradora del ius civile. El término interpretatio tiene para los romanos un significado muy amplio y genérico, ya que indica todo el trabajo propio de la jurisprudencia. En este sentido, como afirma Reinoso Barbero ${ }^{41}$, la interpretatio "comprende la gran labor desarrollada durante siglos por los prudentes, tanto en la creación propiamente dicha del derecho, en la fundación de instituciones y formulación de reglas y principios a través de una fecundísima casuística, como en la integración y adecuación a las relaciones y contingencias humanas de todo el derecho establecido en su más amplio sentido». A su vez, matiza que el que la interpretatio sea creadora de Derecho y distinta esencialmente de la moderna interpretación es del todo exacto sólo en orden al ius civile, debido a que se establecía una precisa equivalencia entre ius civile e interpretatio, dado que, en cuanto a las leyes, los Senadoconsultos, el Edicto de los pretores y las Constituciones Imperiales no ocurría lo mismo, pues en ellas los juristas están ligados al texto y al espíritu de las leyes ${ }^{42}$.

La labor del jurisprudente no es remunerada, no está encaminada a obtener un lucro o interés económico. Está basada en la Iustitia y en la utilitas. Un texto Ulpiano, recogido en D.1,1,10,2, tras definir en el párrafo primero lo que es Iustitia $^{43}$ como la voluntad constante y perpetua de dar a cada uno su derecho, dice que la juris-

40 Reinoso Barbero, F., Iuris Auctores (reflexiones sobre la jurisprudencia romana y el jurista actual), en Estudios de Derecho Romano en honor al profesor Álvaro d'Ors, Vol II, Edit. Ediciones Universidad de Navarra (EUNSA), Pamplona, 1987, pág. 982.

41 Reinoso Barbero, F., Iuris Auctores (reflexiones sobre la jurisprudencia romana y el jurista actual, en Iuris Auctores), op. cit., pág. 991.

42 No obstante, respecto a estas formaciones autónomas y autoritarias, no puede decirse que la interpretatio sea meramente declarativa, ya que existe una influencia de la jurisprudencia en los distintos ámbitos de los ordenamientos o complejos jurídicos a través de agrupamientos de instituciones afines y de extensión de principios de unos a otros sistemas, así como construyó las bases y proporcionó los elementos para la fusión de los ordenamientos jurídicos (ius civile, ius honorarium, ius novum) en un sistema unitario. A su vez, la labor del iurisconsultus es inspiradora de toda innovación y transformación del Derecho realizada por los órganos oficiales, bien directamente sugiriendo remedios y medidas a los pretores y emperadores o, bien indirectamente, haciendo sentir la falta de una determinada reforma inspirada en las necesidades y contingencias sociales. Además, a la función del jurista, consagrada por una práctica y un prestigio multisecular, se la dota de un carácter público, que se le reconoce oficialmente y, al mismo tiempo, se controla y centraliza en el ius publice respondendi. Vid. REINoso BARBERO, F., Iuris Auctores (reflexiones sobre la jurisprudencia romana y el jurista actual), op. cit., pág. 993.

${ }_{43}$ D.1,1,10pr. Ulpianus libro primo regularum [...] Iustitia est constans et perpetua voluntas ius suum cuique tribuendi [...] 
prudencia versa sobre el conocimiento de las cosas divinas y humanas, así como la define como la ciencia de lo justo y lo injusto.

D.1,1,10,2 Ulpianus libro primo regularum.

[...] Iuris prudenti<a> est divinarum atque humanarum rerum notitia, iusti atque iniusti scientia [...]

Sentada la diferencia expuesta en los párrafos anteriores, y prosiguiendo con el fragmento de Ulpiano, en D.50,13,1,12.13, el jurista, al tratar de los honorarios de los abogados, alude a la prohibición de la denominada quota litis y a los límites máximos a los que pueden ascender estos, así como a la prohibición impuesta a los herederos del difunto de reclamar las retribuciones ya pagadas por éste a su defensor.

D.50,13,1,12.13 Ulpianus octavo de omnibus tribunalibus.

[...] Si cui cautun es honorarium vel si quis de lite pactus est, videamus an petere possit. Et quidem de pactis ita est rescriptum ab imperator nostro et divo patre eius: "Litis causa malo more pecuniam tibi promissam ipse quoque profiteris. Sed hoc ita est si suspensa litem societate futuri emolumenti cautio pollicetur. Si vero post causam actam cauta est honoraria summa, peti poterit usque ad probabilem quamtitatem, etsi momine palmarii cautum, sic tame nut computetur id quod datum est cum eo quod debetur neutrumque compostitum licitam qualitatem excedat». Licita autem quamtitas intellegitur pro singulis causis usque ad centrum áureos [...] Divus Severus ab heredibus advocati mortuo eo prohibuit mercedem repeti, quia per ipsum non steterat, quo minus causam ageret $[\ldots]$

Como se advierte, los honorarios de los abogados son sometidos a control, en cuanto al máximo admitido, fijado en «cien áureos por causa» - o diez mil sextercios, como así es cifrado en tiempos de los emperadores Claudio y Trajano-. A su vez, como puede también observarse, se admite que el abogado se haga entregar cierta cantidad de dinero en concepto provisión de fondos por su cliente ${ }^{44}$.

D.17,1,6pr. Ulpianus libro trigensimo primo ad edictum.

[...] Si remunerandi gratia honor intervenit, erit mandati actio [...]

\section{III.B.3. Praeceptores directo civili}

En cuanto a los profesores de Derecho Civil, en D.50,13,1,5, Ulpiano establece, sin embargo, que los gobernadores provinciales no

${ }^{44}$ Respecto a los honorarios de los abogados en el mundo romano, Vid. Agudo RuIz, A., Abogacía y abogados, un estudio histórico-jurídico, op. cit., págs. 179-208. 
juzgarán sobre los salarios respecto aquellos, bajo el argumento de que esta ciencia, aún siendo digna del mayor respeto, no debe valorarse ni envilecerse por un precio en dinero, dado que entonces vendría a reclamarse judicialmente lo que debería haberse ofrecido por el alumno antes de empezar la enseñanza. Entiende el jurista que, aunque haya cosas que pueden ser aceptadas honestamente, no deben ser reclamadas a posteriori sin vulnerar el honor debido.

\section{D.50,13,1,5 Ulpianus libro octavo de omnibus tribunalibus.}

[...] Proinde ne iuris quidem civilis professoribus ius dicent: est quidem res sanctissima civilis sapientia, sed quae pretio nummario non sit aestimanda nec dehonestanda, dum in iudicio honor petitur, qui in ingressu sacramenti offerri debuit. quaedam enim tametsi honeste accipiantur, inhoneste tamen petuntur [...]

Camacho Evangelista ${ }^{45}$ sostiene que, ya desde el siglo III a.C., el jurisconsulto romano no se dedica, única y exclusivamente, a resolver cuestiones jurídicas, sino que aparece rodeado de jóvenes con aspiraciones a la vida pública, los cuales se convierten en una especie de alumnos que esperan adquirir los conocimientos adecuados en la ciencia del Derecho. En opinión de este autor, la confusión entre jurisconsulto y profesor de Derecho se mantendrá durante toda la época clásica. Ya el jurista Pomponio, en D.1,2,2,35, refiere que, antes del jurisconsulto Tiberio Coruncano, que señala como el primero de los juristas, nadie profesaba públicamente el Derecho Civil, pues todos los que le precedieron procuraban mantener dicha ciencia en secreto, atendiendo sólo a las consultas que se les hacía, mas no enseñando a los que deseaban aprender.

\section{D.1,2,2,35 Pomponius libro singulari enchiridii.}

[...] Iuris civilis scientiam plurimi et maximi viri professi sunt: sed qui eorum maximae dignationis apud populum Romanum fuerunt, eorum in praesentia mentio habenda est, ut appareat, a quibus et qualibus haec iura orta et tradita sunt. Et quidem ex omnibus, qui scientiam nancti sunt, ante Tiberium Coruncanium publice professum neminem traditur: ceteri autem ad hunc vel in latenti ius civile retinere cogitabant solumque consultatoribus vacare potius quam discere volentibus se praestabant $[\ldots]$

La calidad del jurisconsulto es, a principios de la época imperial, objeto de una consagración oficial bajo la forma del inius publicae respondendi, por la que algunos juristas verán que sus respuestas jurídicas se encuentran amparadas ex autoritate principis, lo que significa dar carácter formal de Derecho positivo a la doctrina cientí-

\footnotetext{
45 Camacho Evangelista, F., Las profesiones liberales en Roma, op. cit., págs. 30-31.
} 
fica elaborada por los mismo. Ello influye de manera decisiva en los alumnos a la hora de elegir profesor de Derecho.

Durante toda la época clásica los profesores de Derecho se confunden con los prudentes ${ }^{46}$. A estos jurisconsultos no se les suele remunerar, ya que, al pertenecer en su mayor parte a la clase patricia, así como en ocasiones al beneficiarse del favor imperial, son personas económicamente pudientes. No obstante, se dan casos excepcionales, como el que se relata en D.1,2,2,50 ${ }^{47}$, donde se informa de que el jurista Sabino es ayudado por sus discípulos, de lo que se deduce que, por ofrecer sus conocimientos a sus oyentes, este jurista recibe algún tipo de recompensa a título privado.

La situación descrita cambia radicalmente durante el Bajo Imperio, tanto por la desaparición de la figura del jurisconsulto como por la existencia de instituciones de enseñanza superior ${ }^{48}$. En este momento el profesor se desliga del jurisconsulto y se transforma en un profesional de la enseñanza, con lo que no hay obstáculo alguno para que se vea recompensado por los servicios prestados. En esta época viene a coincidir con la consolidación de la fusión de las figuras de abogado y jurisconsulto, interviniendo en el proceso de la cognitio extraordinem tan sólo el advoctus, el cual debía tener una adecuada formación en la ciencia del Derecho.

Expone Agudo Ruiz ${ }^{49}$ que, en el año 460 d.C., una Constitución del emperador León I, dirigida a Viviano, prefecto del pretorio de la ciudad de Constantinopla, recogida en CI.2,7,11,1, viene a sancionar por primera vez, la necesidad de que los futuros abogados acrediten tener conocimientos jurídicos. Como resulta evidente, dicha acreditación debe ser expedida por los profesores que imparten sus clases, oficialmente, en la Escuela de Derecho de Constantinopla, tras haber superado el alumno el correspondiente examen.

Dicha constitución fue recogida en el Codex Iustinianus.

46 Se llamar auditores a los que siguen a los juristas oficialmente autorizados para dar respuestas, en lugares públicos, a cuestiones planteadas por los particulares en relación a los conflictos de interereses que les pudieren surgir y, que, en un principio, eran razonadas y argumentadas brevemente, trayendo a colación respuestas de juristas precendentes; Vid. García Garrido, M.J., Eugenio Díaz, F., Estudios de Derecho y formación de juristas, Edit. Dykinson, Madrid, 1988, págs. 39-46.

${ }^{47}$ D.1,2,2,50 Pomponius libro singulari enchiridii. [...] Ergo Sabino concessum est a Tiberio Caesare, ut populo responderet: qui in equestri ordine iam grandis natu et fere annorum quinquaginta receptus est. huic nec amplae facultates fuerunt, sed plurimum a suis auditoribus sustentatus est [...]

48 Camacho Evangelista, F., Las profesiones liberales en Roma, op. cit., págs. 30-31.

49 Agudo Ruiz, A., Abogacía y abogados, un estudio histórico-jurídico, op. cit., pág. 97. 
CI.2,7,11,1 Imp. Leo A. Viviano.

[...] Iurisperitos etiam doctores eorum iubemus iuratos sub gestorum testificatione depromere, ese eum, qui postbac subrograri voluerit, peritia iuris instructum [...]

Por tanto, si bien durante la época clásica, en la que puede sostenerse la confusión entre el jurisconsulto y profesor de Derecho, no es habitual el establecimiento de honorarios en favor de éstos, en el Bajo imperio, con la aparición de instituciones de enseñanza superior, empieza a considerarse profesionales a los profesores que imparten clases de Derecho, por lo que no debe haber objeción alguna para que se les retribuya por los servicios que prestan.

\section{III.B.4. Philosophi}

En cuanto a los filósofos, Ulpiano, en D.50.13,1,4, dice que éstos no deben considerarse como los preceptores aludidos en D.50,13,1 pr., pero no porque no sean dignos, sino porque han de empezar profesando el desprecio por el trabajo servil.

\section{D.50,13,1,4 Ulpianus libro octavo de omnibus tribunalibus.}

[...] An et philosophi professorum numero sint? et non putem, non quia non religiosa res est, sed quia hoc primum profiteri eos oportet mercennariam operam spernere [...]

Camacho Evangelista ${ }^{50}$ afirma que, Ulpiano, al dejarse influir por los estoicos de la época imperial, piensa que el desprecio del dinero y de las riquezas hace lógico que los filósofos, aunque realicen una profesión liberal, no tengan acceso a la jurisdicción del pretor para exigir el pago de honorarios. El autor apunta que, para dar tal respuesta, Ulpiano también se inspira en un rescripto de Antonino Pío, citado por Modestino y recogido en D.27,1,6.

\section{III.B.4. Agrimensores}

En cuanto a los agrimensores, Ulpiano se refiere a ellos en D.50,13,1pr., al tratar de los preceptores. Las actividades desempeñadas por estos profesionales son, por un lado, técnicas y, por otro, judiciales. Dentro de las primeras, la parcelación de la superficie de tierra a asignar se corresponde con la más importante. En ella se comprendían todas las operaciones necesarias para orientar y tra-

${ }^{50}$ Camacho Evangelista, F., Las profesiones liberales en Roma, op. cit., págs. 33-34.

(C) UNED. Revista de Derecho UNED, núm. 24, 2019 
zar los ejes principales, para realizar mediciones salvando los obstáculos naturales, la colocación de los termini en las intersecciones, la realización de la forma, etc.; a ésta hay que añadir todas aquellas operaciones en las que la realización y el cálculo de mediciones eran imprescindibles: la tasación de propiedades en las operaciones de compra-venta, la restitución de los termini desaparecidos o trasladados de su posición original, la inspección de los confines, etc. Pero, su principal actividad era actuar como iudices, arbitri o advocati en las controversiae agrorum, para lo cual el agrimensor se debía comportar como un hombre prudente, bueno y justo, no dejarse llevar ni por la ambición ni por la vileza y, en todo momento, ser fiel a su creencia, a su disciplina y a las costumbres.

Por lo tanto, en la formación del agrimensor, y en relación con el aspecto técnico de la disciplina, eran de gran importancia los conocimientos sobre geometría, astronomía, cosmología, etc.; y en sus funciones de juez, árbitro o abogado, debía conocer todo lo relacionado con las diferentes condiciones jurídicas del suelo, las leyes de las colonias y municipios, los edictos del emperador y de los gobernantes y, sobre todo, la doctrina jurídica de la controversia agroru ${ }^{51}$. Aunque no eran técnicos en Derecho, se consideraban auxiliares indispensables en los negocios jurídicos relacionados con la propiedad fundiaria.

\section{III.B.5. Medici}

Finalmente, en lo que respecta al ámbito de la medicina, en D.50,13,1,1, Ulpiano afirma que los que se dedican a este ámbito del saber son como los profesores, pero los sitúa en una posición más elevada que éstos, al considerarlos más dignos, porque cuidan de la salud de los hombres ${ }^{52}$.

51 Castillo Pascual, M. ${ }^{a} . J .$, El vocabulario jurídico de los agrimensores romanos, en Brocar (Cuadernos de investigación histórica), N. ${ }^{\circ}$ 19, La Rioja, 1995, págs. 8-9.

${ }^{52}$ En el mismo sentido, en relación a los médicos que se dedican a una concreta especialidad, Ulpiano incluye dentro de esta categoría a los que se ocupan de una determinada parte del cuerpo o de un dolor específico, como el de oído, el de fístula o el de dientes. En definitiva, a los que se ocupan de una especialidad concreta de la medicina. A su vez, matiza el jurista que no pueden entenderse como médicos aquellos que se dedican a la cura por ensalmos, imprecaciones, los curanderos y los que se dedican a los «exorcismos», ya que no pueden encuadrarse estas prácticas dentro del ámbito de la medicina, aunque en ocasiones haya quienes aseguran que con su proceder hayan obtenido algún resultado favorable. Del siguiente fragmento que se trascribe, se deduce que el que se dedicaba a la medicina general tenía mayor prestigio social que los que se dedican a una especialidad concreta. D.50,13,1,3 Ulpianus libro octavo de omnibus tribunalibus [...] Medicos fortassis quis accipiet etiam eos, qui ali- 
D.50,13,1,1 Ulpianus libro octavo de omnibus tribunalibus.

[...] Medicorum quoque eadem causa est quae professorum, nisi quod iustior, cum hi salutis hominum, illi studiorum curam agant: et ideo his quoque extra ordinem ius dici debet [...]

\section{NATURALEZA JURÍDICA DE LAS RELACIONES PRIVADAS QUE ESTABLECEN ESOS PROFESIONALES CON SUS CLIENTES EN EL DESEMPEÑO DE LA ACTIVIDAD QUE LE ES PROPIA}

Gran parte de la doctrina actual, al igual que la Pandectística alemana del siglo XIX, entiende que, en la Roma antigua, las relaciones jurídico-privadas que se establecen entre los profesionales que aquí analizamos con los que demandaban sus conocimientos técnicos revisten carácter contractual y, en concreto, les son de aplicación la regulación y los principios rectores del tipo contractual del mandato. Así, entre otros, Fernández De Buján F.53, quien afirma que, en el mundo antiguo en general, y en la sociedad romana en particular, «no se recondujeron al esquema contractual del arrendamiento de servicios, los trabajos realizados por las denominadas profesiones liberales», sostiene "se entiende que la prestación de sus servicios es, en cierto sentido, impagable por ser difícil, cuando no imposible, cuantificar su valor». Por ello, llega a la conclusión de que «fue frecuente que estos profesionales y otros muchos que ejercían laborales intelectuales, científicas o artísticas, enmarcasen las relaciones con sus clientes en el ámbito del mandato y no del arrendamiento de servicios [...] Nótese además que para referirse a la retribución que se da a estos profesionales no suele emplearse la voz renta, salario o merced. Por el contrario, la expresión frecuentemente utilizada es la de honor u honorario, que todavía se sigue utilizando para referirse a las retribuciones de los servicios prestados por un médico, un abogado o un arquitecto».

cuius partis corporis vel certi doloris sanitatem pollicentur: ut puta si auricularius, si fistulae vel dentium. Inon tamen si incantavit, si inprecatus est, si, ut vulgari verbo impostorum utar, si exorcizavit: non sunt ista medicinae genera, tametsi sint, qui hos sibi profuisse cum praedicatione adfirment [...]. Ulpiano asimila las comadronas (parteras) a los médicos. D.50,13,1,2 Ulpianus libro octavo de omnibus tribunalibus [...] Sed et obstetricem audiant, quae utique medicinam exhibere videtur [...]. Lo mismo hace el jurista en relación a las nodrizas. D.50,13,1,14: [...] Ad nutricia quoque officium praesidis vel praetoris devenit: namque nutrices ob alimoniam infantium apud praesides quod sibi debetur petunt. sed nutricia eo usque producemus, quoad infantes uberibus aluntur: ceterum post haec cessant partes praetoris vel praesidis [...]

${ }^{53}$ Fernández De Buján, F., Sistema contractual romano, op. cit., pág. 356.

(C) UNED. Revista de Derecho UNED, núm. 24, 2019 
Sin embargo, una minoría de autores entiende que, en la época que nos ocupa, las relaciones a las que nos referimos no son subsumibles dentro del contrato de mandato. Entre éstos, Camacho Evangelista ${ }^{54}$, para llegar a tal conclusión, en primer lugar, sostiene que las profesiones liberales «escapan de la noción de responsabilidad contractual», al punto que afirma «Es difícil pedir cuenta a un profesor, o a un médico o a un abogado. El caso particular del agrimensor, de que no responde más que por dolo, confirma la regla. (D.11,6,1). A los titulares de profesiones liberales en el Derecho romano no se les podía hacer responsables de los daños que por su actuación se hubiese sufrido, y la acción de justicia que nace de un contrato se funda, corrientemente, sobre la responsabilidad contractual». En segundo lugar, aduce la concurrencia de otro elemento que es necesario tener en cuenta, tal como que «el titular de una profesión liberal es el especialista altamente cualificado, que el cliente escoge por sus cualidades, que cree le convienen, lo que excluye lógicamente todo recurso posterior. En tal sentido un párrafo del Digesto (D.11,6,1,1) aclara que si el práctico nos defrauda, sufra el daño la persona que torpemente lo escogió». Por último, y tercer lugar, mantiene que las profesiones liberales, al estar ligadas, íntimamente, a la amicitia, en la Roma antigua se ha tenido siempre «escrúpulos de mezclar con derechos y tribunales a las relaciones de amistad, pues las sanciones naturales de la amistad son la opinión y el prestigio social».

En nuestra opinión, que es plenamente coincidente con la de la doctrina mayoritaria al respecto, las relaciones jurídico-privadas que, en el mundo romano antiguo, establece el profesional liberal con sus clientes, en el desempeño de la actividad que le es propia, son encuadradas por la jurisprudencia clásica dentro del contrato de mandato. Así, no podemos compartir lo afirmado por Camacho Evangelista, en lo que respecta a que las profesiones liberales escapan a la noción de responsabilidad contractual ${ }^{55}$. Como apunta 43.

${ }^{54}$ Camacho Evangelista, F., Las profesiones liberales en Roma, op. cit., págs. 40-

55 Es más, ya de antemano, si se analiza el propio texto recogido en D.11,6,1, se deduce la pretensión de incluir las relaciones del agrimensor dentro del régimen contractual, dado que Upiano manifiesta que, desde los antiguos, el contrato de arrendamiento se entiende contrario a la dignidad del agrimensor, lo que indica que debe ser encudrado en otro tipo. D.11,6,1 Ulpianus libro vicensimo quarto ad edictum [...] Adversus mensorem agrorum praetor in factum actionem proposuit. a quo falli nos non oportet: nam interest nostra, ne fallamur in modi renuntiatione, si forte vel de finibus contentio sit vel emptor scire velit vel venditor, cuius modi ager veneat. ideo autem hanc actionem proposuit, quia non crediderunt veteres inter talem personam locationem et conductionem esse, sed magis operam beneficii loco praeberi et id quod datur ei, 
Agudo Ruiz ${ }^{56}$, a partir de la implantación de la congnitio extraordinem, en el mundo romano opera un profundo cambio jurídico, el cual se debe a una importante transformación de la mentalidad, que comienza a incluir en el esquema contractual del mandato las relaciones jurídicas que se dan entre los profesionales analizados y sus clientes. Y es que, en virtud del contrato de mandato surgen obligaciones para el mandatario, que, si no son cumplidas por este último, o de ser cumplidas de manera incorrecta, supone incurrir en responsabilidad. En un supuesto de prestación de determinados servicios por parte de un profesional liberal, el mandatario que los realice debe llevar a cabo el efectivo cumplimiento del encargo encomendado por su mandante, que, a su vez, es libremente aceptado de manera previa por aquél.

Sin embargo, cuando se señala que el mandatario debe cumplir con el encargo recibido, no ha entenderse que deba conseguir, de manera efectiva y con éxito, el fin último pretendido por el mandante, dado que la obligación ha de considerarse como una obligación de medios o actividad y no de resultado. Además, es evidente que, en este caso, el encargo del mandante debe reputarse efectuado de manera abstracta, es decir, sin unas instrucciones concretas y pormenorizadas, dado que la sabiduría y la pericia sobre un ámbito de cocimiento concreto (abogacía, medicina, etc.) la ostenta y posee el mandatario, quien habrá de desempeñar su función de conformidad con sus conocimientos y de acuerdo a los principios y reglas que rigen su profesión o lex artis. La falta de instrucciones dadas por el mandante, para el cumplimiento del encargo, no debe llevar a creer que se trata de un caso de indeterminación de la obligación, por la que el mandato devendría nulo, ya que lo que siempre ha de quedar determinado, o ser susceptible de determinación, es el objeto del mandato, es decir, la labor o gestión que se encomienda ${ }^{57}$ (en este caso los servicios del profesional). Nada obsta para que el mandante, que plenamente confía en el buen hacer del mandatario, deje a este

ad remunerandum dari et inde honorarium appellari: si autem ex locato conducto fuerit actum, dicendum erit nec tenere intentionem. (1) Haec actio dolum malum dumtaxat exigit: visum est enim satis abundeque coerceri mensorem, si dolus malus solus conveniatur eius hominis, qui civiliter obligatus non est. proinde si imperite versatus est, sibi imputare debet qui eum adhibuit: sed et si neglegenter, aeque mensor securus erit: lata culpa plane dolo comparabitur. sed et si mercedem accepit, non omnem culpam eum praestare propter verba edicti: utique enim scit praetor et mercede eos intervenire. (2) Is autem tenetur hac actione qui renuntiavit: sed renuntiasse et eum accipere debemus, qui per alium renuntiavit $[\ldots]$

56 Agudo Ruiz, A., Abogacía y abogados, un estudio histórico-jurídico, op. cit., pág. 174.

57 Fernández De Buján, F., Sistema contractual romano, op. cit., pág. 363.

(C) UNED. Revista de Derecho UNED, núm. 24, 2019 
total libertad a la hora de su ejecución ${ }^{58}$, como realmente sucede en el momento de contratar y encargar un determinado servicio a un profesional liberal, que es quien posee los conocimientos teóricos y técnicos inherentes a su profesión. Por tanto, de no ser llevado a cabo el encargo encomendado por el mandante, en este caso la labor profesional, o de no ser ejecutado conforme a sus conocimientos, o a los principios y reglas de su profesión o lex artis, con actuación negligente, existe responsabilidad contractual del mandatario prestador del servicio, quien responderá por dolo, en el primer caso, y por culpa, en el segundo.

En cuanto a la responsabilidad por culpa, ya en época clásica se habla de este grado de responsabilidad contractual (culpa lata), como puede apreciarse en D.17,1,8,10. En este sentido Fernández De Buján F. ${ }^{59}$ sostiene que no puede precisarse con certeza en que momento los juristas ampliaron la responsabilidad del mandatario hasta la culpa leve.

D.17,1,8,10 Ulpianus libro trigensimo primo ad edictum.

[...] proinde si tibi mandavi, ut hominem emeres, tuque emisti, teneberis mihi, ut restituas. sed et si dolo emere neglexisti (forte enim pecunia accepta alii cessisti ut emeret) aut si lata culpa (forte si gratia ductus passus es alium emere), teneberis. sed et si servus quem emisti fugit, si quidem dolo tuo, teneberis, si dolus non intervenit nec culpa, non teneberis nisi ad hoc, ut caveas, si in potestatem tuam pervenerit, te restituturum. sed et si restituas, et tradere debes. et si cautum est de evictione vel potes desiderare, ut tibi caveatur, puto sufficere, si mihi hac actione cedas, ut procuratorem me in rem meam facias, nec amplius praestes quam consecuturus sis [...]

Es lógico que la falta de actividad, aun no dolosa, sea imputable al mandatario, así como defrauda al mandante el que no pone la diligencia debida en la realización del encargo encomendado.

D.17,1,6,1 Ulpianus libro trigensimo primo ad edictum.

[...] Si cui fuerit mandatum, ut negotia administraret, hac actione erit conveniendus nec recte negotiorum gestorum cum eo agetur: nec enim ideo est obligatus quod negotia gessit, verum idcirco quod mandatum susceperit: denique tenetur et si non gessisset [...]

En época postclásica queda consolidada la responsabilidad del mandatario, que será confirmada en el período justinianeo, en donde se amplía definitivamente su responsabilidad hasta por culpa leve.

58 D.17,1,3,1 (Paul. 22 ed.); este fragmento puede servir de fundamento para entender que el contrato de mandato se puede confeccionar aun sin instrucciones exactas del mandante.

${ }^{59}$ Fernández De Buján, F., Sistema contractual romano, op. cit., pág. 367. 
En otro sentido, lo que alude Camacho Evangelista, para dar mayor fuerza a sus argumentos, en relación a lo dicho sobre el agrimensor en D.11,6,1, en cuanto a que éste no responde más que por dolo, no es, con el respeto debido, del todo correcto, dado que en dicho fragmento se señala que el agrimensor también responderá si obró con negligencia, equiparándose la culpa al dolo ${ }^{60}$.

Además, como se ha expuesto, este autor, para excluir la aplicación del mandato, utiliza también como argumento el hecho de que, si una persona escoge a un profesional que cree le conviene en virtud de sus cualidades, y éste le defrauda, debe sufrir el daño la persona que torpemente lo escogió. Se ampara para ello también en lo establecido en D.11,6,1,1, precepto relativo a los agrimensores, como se ha visto. Por nuestra parte, entendemos que el que una persona escoja a un determinado profesional, en virtud de sus cualidades, el hecho de haberse confundido en la elección, no cumpliendo las expectativas previstas - lo que incluso no dejaría de ser en muchos casos una valoración subjetiva-, no tiene nada que ver con el hecho de que el elegido incurra en dolo o culpa en la realización de la prestación. En el primer caso, es evidente que no es responsabilidad del profesional liberal el no ajustarse a las cualidades que el cliente, en su momento, estimó que poseía. Pero, en el segundo caso, sin embargo, el profesional, o no cumplió con el encargo aceptado, o no actuó con la debida diligencia, supuestos en los que sí sería contractualmente responsable, al incurrir en dolo o culpa.

Además, otro argumento que ampara nuestra postura, es decir, la aplicación del contrato de mandato a estas relaciones se fundamenta en poner en relación el fragmento de Ulpiano, recogido en D.50,13,1, ya expuesto, con otro texto de este mismo jurista, recogido en D.17,1,6pr.

\section{D.17,1,6pr. Ulpianus libro trigensimo primo ad edictum. \\ [...] Si remunerandi gratia honor intervenit, erit mandati actio [...]}

De lo dicho en el párrafo transcrito, puede deducirse que, en determinados supuestos, el mandato es retribuido a través de honorarios, como es el caso de los que se dedican a las profesiones más dignas, las liberales, las cuales se encuentran fuera de la aplicación de la locatio conductio.

Por último, Camacho Evangelista, para reforzar aún más su postura, refiere que las profesiones liberales están íntimamenbte ligadas a la concepción romana de la amistad, por lo que, debido a este mo-

${ }^{60}$ Veáse texto en nota 55. 
tivo, los romanos siempre han tenido escrúpulos para mezclar con derechos y tribunales tales relaciones. Así, utiliza también tal argumento para justificar la no aplicación del mandato a las relaciones jurídicas que establecen los profesionales objeto de este estudio y sus clientes. Pues bien, tampoco podemos mostrar nuestra conformidad con tal afirmación. De una parte, es necesario resaltar que la amiticia en Roma es considerada como una carga, al poder exigir al amigo hospitalidad, patrocinio, gestión de negocios e incluso préstamo; mas, a sensu contrario, el beneficium podía ser objeto de retribución, como expresión del sentimiento de gratitud.

Como señala Agudo Ruiz ${ }^{61}$, el cumplimiento en la remuneración no depende de la libre y espontánea voluntad del cliente, sino que su obligatoriedad viene impuesta por la costumbre y se dirige a compensar unos servicios que no eran objeto de retribución económica, lo que es consecuencia de una comunidad cimentada sobre el deber de actuar en correspondencia, es decir, de remunerar, de acuerdo a cuestiones éticas y morales que tienen su fundamento último en la filosofía estoica. Este autor también expone, aunque en relación con la profesión de la abogacía, pero que entendemos aplicable al resto de operea liberales, que poco a poco se siente la necesidad de asignar una remuneración, exigible no por medio del procedimiento formulario, sino de cognitio extraordinem ${ }^{62}$. A partir de entonces, si bien desde un principio los romanos fueron refractarios a encuadrar dentro de los esquemas contractuales la labor desempeñada por los profesionales liberales, se opera un profundo cambio jurídico. Así, prosigue Agudo Ruiz ${ }^{63}$ exponiendo que el cambio se debe a una profunda transformación de la mentalidad romana, que considera que, el percibir una retribución, entendida ésta como contraprestación, a la ejecución de determinados servicios, es impropio de determinadas profesiones, por lo que el salario calificado de merced queda reducido al esquema de la locatio conductio, y era exclusivamente aplicable a servicios manuales, reputados como inferiores, considerando, en consecuencia, que se reducen a la categoría del mandato los servicios prestados por los que se dedican a las operae liberales. Ahora bien, cuando

${ }^{61}$ Agudo Ruiz, A., Abogacía y abogados, un estudio histórico-jurídico, op. cit., pág. 170.

${ }_{62}$ El procedimiento extraordinario aparece en Roma y en Italia a partir de Augusto y, especialmente, desde Adriano, cuando el emperador faculta a un cónsul o a un magistrado para que intervenga en determinados asuntos, que considera de particular interés. En la época de Septimio Severo la cognitio extraordinaria se implanta definitivamente. Vid. García Garrido, M.J., Fernández De Buján F., Fundamentos clásicos de la democracia y de la administración, op. cit., págs. 276-277.

63 Agudo Ruiz, A., Abogacía y abogados, un estudio histórico-jurídico, op. cit., págs. 175-177. 
la práctica social permite que quien presta estos servicios profesionales reciba, como consecuencia de los mismos, una retribución, que denominan honorarius - y no merces - y, además, cuando se faculta para reclamar dichos honorarios por la vía judicial de la cognitio extraordinem, se hace necesario admitir que, si bien el mandato en su regulación y contenido jurídico permanece en el procedimiento anclado en su viejo esquema de negocio gratuito, esta nota de gratuidad en el normal devenir social de nuestro contrato se desvanece o desvirtúa, debido a la pérdida del sentido originario y de la finalidad esencial para la cual fue, en un principio, concebida. Por ello, numerosos supuestos de mandato convierten arcaicos y anacrónicos los parámetros extrajurídicos que habían hecho nacer tal relación contractual, al poder fundamentar la institución, en épocas más avanzadas, en otros aspectos distintos a los deberes morales y éticos.

\section{CONCLUSIÓN}

En definitiva, de todo lo expuesto puede concluirse que las profesiones liberales (medicina, abogacía, arquitectura, etc.) encuentran su origen en la antigüedad, especialmente, en la civilización romana, momento en el que van tomando cuerpo una serie de notas distintivas que las caracterizan y que la tradición romanística ha hecho que permanezcan en esencia, sin perjuicio de su evolución a lo largo de la historia.

Así, el concepto, con sus connotaciones, tiene su origen último en Roma, cristaliza con la recepción en Europa del Derecho Romano en época del ius commune, es decir, en la Baja Edad Media y en la era moderna, con el nacimiento y expansión de los centros universitarios, como corporaciones que pasan a ostentar el monopolio de los studia generalia -Ulpiano utiliza ya la expresión studiorum liberalium en D.50,13,1 pr-, al impartir, en la facultades de artes liberales, las disciplinas que integrantes del trívium (gramática, dialéctica y retórica) y el quadrivium (aritmética, geometría, astronomía y música), y los conocimientos que conciernen a las facultades superiores de leyes, medicina y teología - a las que, con posterioridad, se sumará la arquitectura-, y con la constitución de los Estados Nación, hasta tomar cuerpo definitivo en la actualidad y designar, conjuntamente, como profesiones liberales, a una serie de actividades u ocupaciones, por presentar características propias.

Con lo cual, desde Roma, las notas esenciales que caracterizan a este tipo de profesiones se han ido manteniendo, sirviendo de pre- 
supuestos característicos respecto a las mismas. Notas esenciales, como la intelectualidad, la autonomía, la independencia y la libertad, así como la colegiación obligatoria, como elemento distintivo ${ }^{64}$, se erigen en elementos definidores e identificativos respecto al resto de profesiones u oficios. El alto componente intelectual de estas profesiones, como característica esencial, se ha mantenido intacto desde la Roma antigua hasta la actualidad. Otro tanto puede decirse sobre nota de la autonomía, cuando menos técnica, que se erige en otra característica común y esencial a todas ellas, connotación interrelacionada con otras insoslayables, tales como la libertad y la independencia.

García Testal ${ }^{65}$ sostiene que, en la actualidad, la caracterización de lo que tradicionalmente se conoce como profesional liberal viene determinado por tres factores, que identifica con los siguientes: La posesión de una titulación (se trata de actividades eminentemente intelectuales, para cuyo ejercicio el legislador ha impuesto la previa posesión de unos conocimientos amparados por un título); la obligatoriedad de inscripción en el colegio profesional correspondiente; y el desarrollo de su prestación de servicios con grandes dosis de autonomía técnica. Sin embargo, a nuestro entender, aunque la incorporación a un collegium sea aplicable con carácter general para el ejercicio de las profesiones liberales, no resulta requisito exigible en determinados supuestos, en los que sí concurren los de intelectualidad y autonomía técnica y, por ende, el libertad e independencia al respecto, por lo que, aun sirviendo como elemento distintivo y definidor a tener presente, no puede considerarse como una nota esencial $^{66}$.

${ }^{64}$ La matriculación o inscripción en un collegium para realizar determinadas profesiones, como la abogacía, comienza a exigirse en el Baja Imperio Romano, como mecanismo de control ejercido por los emperadores.

65 García Testal, E., La cuestinonada aceptación del ejercicio asalariado de profesiones liberales, en El trabajo profesional de los abogados, Edit. Tirant Lo blanch, Valencia, 2012, págs. 19-20.

${ }_{66}$ Sin embargo, Alonso Pérez entiende que la verdadera nota que caracteriza a las profesiones aquí analizadas, diferenciándolas del resto, se corresponde con la de colegialidad. La autora sostiene que las notas de liberalidad e intelectualidad no resultan eficaces en la actualidad para definirlos; Vid. Alonso PÉrEZ, M. ${ }^{\mathrm{a}}$.J., Los contratos de servicios de abogados, médicos y arquitectos, Edit. J.M. Bosch, Barcelona, 1997, págs. 35-40. 